\title{
The Influence of Organizational Structure on International Purchasing Success
}

\author{
Research-in-Progress
}

\author{
Tabea Tressin \\ Hamburg University of Technology, Institute for \\ Human Resource Management and Organizations, \\ Schwarzenbergstraße 95 (D), 21073 Hamburg, \\ Germany. Tel: +49 40 42878-3567. \\ Email: tabea.tressin@tuhh.de.
}

\author{
Nicole Franziska Richter \\ Nordakademie, Professorship of Marketing and \\ General Management, Koellner Chaussee 11, 25337 \\ Elmshorn, Germany, Tel: +49 4121 4090-241. Email: \\ nicole.richter@nordakademie.de.
}

\section{David F. Midgley}

INSEAD, Professor of Marketing, Boulevard de Constance, 77305 Fontainebleau Cedex, France, Tel: +33 160724977. Email: david.midgley@insead.edu.

\begin{abstract}
International purchasing is one of the most important strategic topics for managers and attracts more and more interest among researchers. Yet, research often lacks strong theoretical and systematic insights on the intricacies of purchasing success and does not make enough use of advanced empirical methods.

We apply a structural equation modeling technique to better research into the intricacies of higher or lower purchasing performance owing to different organizational design choices. We build our model on the resource-based view and on transaction cost economics and make use of survey data of purchasers engaging in international sourcing activities.

We find four important drivers of purchasing performance, namely specialization, configuration, standardization and centralization. The importance of these drivers seems to be contingent on the sourcing environments, namely on the characteristics attributed to high cost and low cost countries.
\end{abstract}

Keywords: International Purchasing, Global Sourcing, Emerging Markets, Organizational Structure, Structural Equation Modeling 


\section{Introduction}

International purchasing is one of the most important strategic topics for managers, and attracts more and more interest among researchers (de Beuckelaer \& Wagner, 2007; Hultman, Johnsen, Johnsen, \& Hertz, 2012). Yet research often still lacks strong theoretical and systematic insights on the intricacies of purchasing success and does not make enough use of advanced empirical methods (see for instance Murray, Kotabe, \& Zhou, 2005; Quintens, Pauwels, \& Matthyssens, 2006b; Tressin \& Richter, 2014).

Hence, while most research in the field remains stuck in a descriptive discourse, we will apply a structural equation modeling technique to better research into the intricacies of higher or lower purchasing performance owing to different organizational design choices. In doing so, we build our causal model on the resource-based view and transaction cost economics and make use of a research platform identified in a recent literature review (Tressin \& Richter, 2014).

\section{The Causal Model and Research Hypotheses}

In the following we outline our causal model of purchasing success. The model has five organizational structure constructs, namely centralization (e.g. Gonzalez-Padron, Hult, \& Calantone, 2008), standardization (e.g. Giannakis, Doran, \& Chen, 2012), specialization (e.g. Wang, Singh, Samson, \& Power, 2011), configuration (e.g. Hartmann, Trautmann, \& Jahns, 2008), and involvement (e.g. Giannakis et al., 2012), hypothesized to positively influence purchasing and therewith firm performance.

Building on the transaction and information cost economics we outline a positive impact of centralization and standardization on purchasing performance and therewith on firm performance. Centralization refers to the concentration or aggregation of decision-making authority in a single organizational unit, for instance at the headquarters level. The overall efficiency of a centrally organized administration of global purchasing activities is supposed to be higher than in a decentralized structure: Since administrative functions involving for instance information processing and monitoring practices are duplicated in decentralized structures (e.g. Galbraith, 1973; Ghoshal \& Nohria, 1993). Standardization refers to the degree to which purchasing activities are defined by rules, standard procedures and tools (such as suppliers rating systems and auditing, information sharing systems, performance reporting, risk planning, and quality management tools). These standards are designed to reduce uncertainty and variation in the outcomes, and are therewith supposed to positively impact purchasing and firm performance (Garrido-Samaniego \& Gutiérrez-Cillán, 2004; Johnston \& Bonoma, 1981; Karjalainen \& Salmi, 2013; Sanchez-Rodriguez, Hemsworth, Martinez-Lorente, \& Clavel, 2006).

Building on the resource-based view, we hypothesize a positive impact of specialization, configuration and involvement on purchasing and firm performance. Specialization refers to the repetitiveness of tasks (Glock \& Hochrein, 2011) and to the extent to which specialized skills are existent in the department. These skills comprise: team building, strategic planning, communication, technical, and financial skills (e.g. Giunipero, Handfield, \& Eltantawy, 2006). These purchasing skills are resources of the firm that lead to operational (purchasing), and hence, firm performance (Kerkfeld \& Hartmann, 2012). Configuration is defined as the purchasing department's status in the company, and thus, its strategic importance and exertion of influence. Giving strategic influence to the purchasing department or especially to the Chief Purchasing Office leads to higher resource access in the firm (in terms of time, human and financial resources). This enhances the purchasing department's capabilities and therewith leads to higher purchasing and firm performance (e.g. Kusaba, Moser, \& Rodrigues, 2011; Weber, Hiete, Lauer, \& Rentz, 2010). Involvement is the 
extent of integration of functional and hierarchical levels (Glock \& Hochrein, 2011) in the purchasing process; often the overall size of a purchasing team is referred to as a measure of involvement (Johnston \& Bonoma, 1981). A higher involvement increases the capabilities used for decision-making and is supposed to positively impact purchasing and firm performance. In their empirical study, Narasimhan and Das (2001) find a positive effect of cross-functional integration on firm performance and Bals, Hartmann, and Ritter (2009) reveal a positive impact of collaboration on purchasing performance in procuring marketing services.

\section{The Sample and Research Methodology}

In order to test the above research hypotheses, we make use of a sample of $n=195$ purchasers interviewed in April-May 2014 by means of a computer assisted telephone interview. The sampling frame was taken from Hoppenstedt's directory of firms and we focused on firms belonging to the manufacturing industry (i.e. European Union's NACE codes $2 * * * *, 30^{* * *}$, and $325^{* *}$ ) and purchasing their goods from international suppliers. The experienced telephone interviewers were all thoroughly briefed beforehand the study. Non-response patterns were checked ex-post and did not point to problems of survey design. The majority of firms surveyed has between 250 and 1999 employees. The sample comprises 37 different sourcing locations (nations in which the major supplier is located), and therewith offers a good platform for the project.

The items used to operationalize the constructs are all taken from the literature (sometimes with slight adaptations) - we referred to the following operationalizations in designing our measurement models: Centralization is taken from Quintens, Pauwels, and Matthyssens (2006a), standardization is a selection of tools presented by Karjalainen and Salmi (2013). Specialization is a collection of the most important skills for purchasing professionals (collected by Giunipero \& Pearcy, 2000; Petersen, Frayer, \& Scannell, 2000; Trent \& Monczka, 2003). Configuration is taken from Paulraj (2011) and the scale used for involvement is based on Bals et al. (2009). Our dependent constructs are purchasing performance, operationalized as changes in purchasing time, cost and quality due to international sourcing activities (see GonzálezBenito, 2007, 2010), and firm performance in terms of improvements of financial (profit target achievement) and non-financial (customer satisfaction, competitive advantage) performance in the past years (see Chen, Tsou, \& Huang, 2009).

To empirically test our hypotheses we make use of PLS-SEM and SmartPLS 3.0 (Ringle, Wende, \& Becker, 2014). Following the procedures outlined in Hair, Hult, Ringle, and Sarstedt (2014), we evaluated the measurement models first. All measurement models are uncritical with loadings, mostly above 0.7 . Regarding our formative constructs, some weights are insignificant; yet, following the procedure recommended by Hair et al. (2014), we renounce eliminating any formative indicators (specialization, standardization) for the sake of the constructs' completeness. Having checked the measurement models, we will concentrate on the results derived for the structural or inner model in the following.

\section{Discussion of Results}

The following figure presents the causal model hypothesized and the results for the total sample ('All') as well as for two subsamples, namely results for those firms sourcing from high cost countries ('HCC') versus firms sourcing from low cost countries ('LCC'). The latter is incorporated, as contingency approaches in purchasing suggest that relationships are contingent on environmental factors (an assumption which will need further theoretical elaboration in 
progressing with this project).

Figure 1: Causal model and results

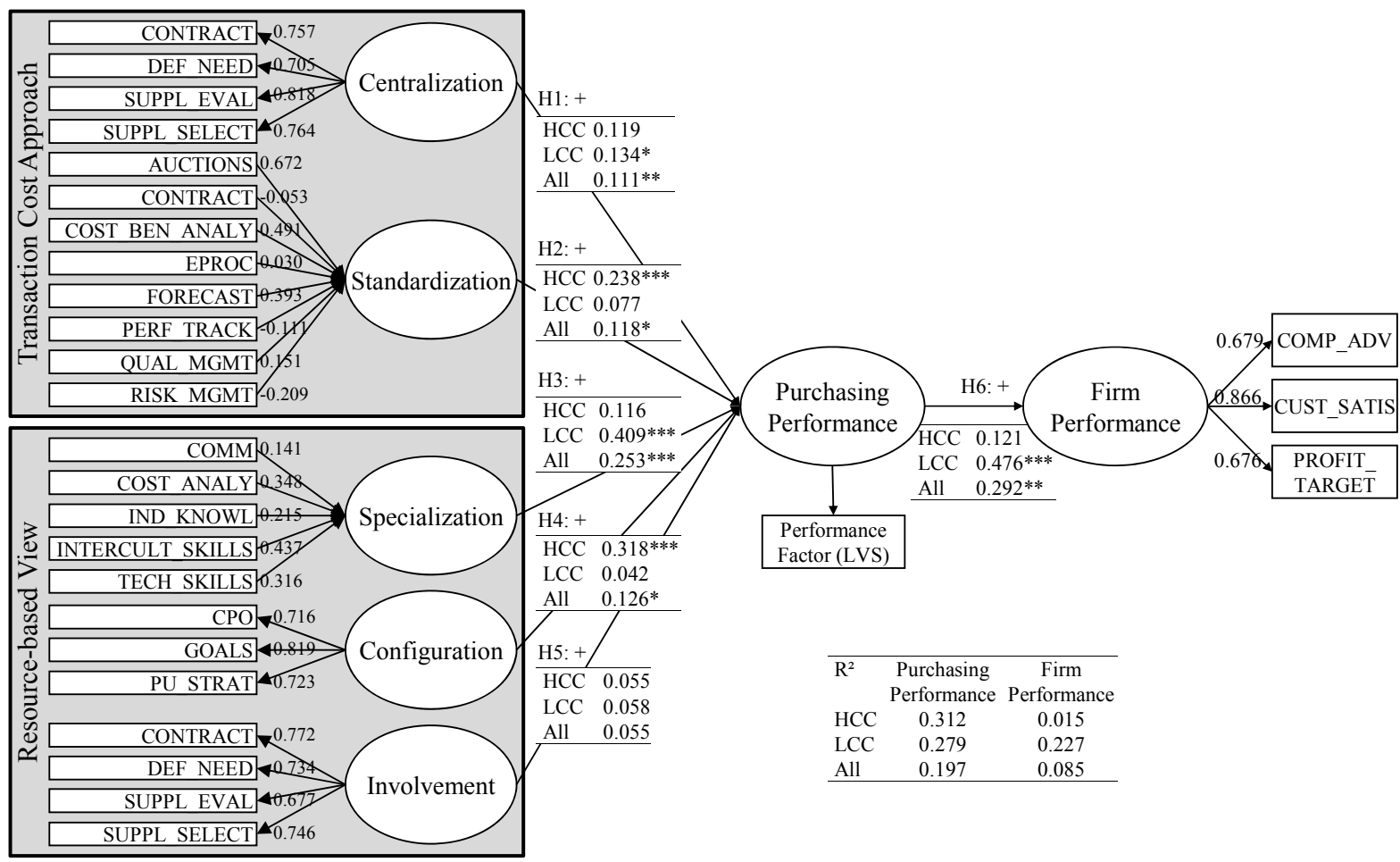

First, looking at the total sample, we find that purchasing performance has a significant and positive effect on firm performance. Second, we find that four out of our organizational structure constructs have a positive and significant impact on purchasing performance (all except for involvement). Therewith, we are able to explain a moderate share of variance in purchasing performance (namely $20 \%$ ). Hence, both, transaction cost economics and the resource-based view contribute to explaining the intricacies of higher or lower purchasing performance. The explanatory power of the model moreover increases considerably, as soon as we are looking at our subgroups - i.e. the relationships found seem to be contingent on environmental factors, namely on the characteristics of high and low-cost countries.

In total, the most important driver of purchasing performance is specialization. Hence, specialization is key for achieving a good purchasing performance in terms of reducing costs, increasing quality and reducing time. Among the skills used to operationalize specialization, we find that especially intercultural, cost analytical, and technical skills seem to be the most relevant drivers of performance. This is followed at a distance by configuration, standardization and centralization - all showing rather comparable path coefficients. Centralized structures in which purchasing process stages such as contract management, supplier selection and evaluation are centralized in one unit are promising in terms of increasing the performance of purchasing departments. Likewise standardization of procedures and tools such as cost-benefit analyses, performance tracking, quality, and risk management induces a higher performance. Finally, configuring the purchasing department in such a way that it has a purchasing strategy and goals aligned with what the top management envisages, drives the performance of purchasing activities up.

These relationships vary or are contingent on the purchasing environments. In high cost countries, two aspects are of specific relevance, namely configuration of purchasing departments and standardization of procedures and tools. I.e. when sourcing from high cost countries, purchasing departments should be given visibility in top management and alignment 
with corporate strategies. Moreover, management needs to make sure that standards are established and followed throughout all purchasing activities to be efficient. In low cost countries, two other aspects are of relevance: Specialization, i.e. the skills available in the purchasing department. Hence, firms need to make sure that their staffing specifically focuses on intercultural, cost analytical, and technical skills of their purchasers. Second, centralization is key for increasing purchasing performance. I.e. firms which centralized their purchasing departments within the home country performed better than decentralized firms when sourcing from low cost countries.

Both subgroup models have a good explanatory power (of $28 \%$ respectively $31 \%$ ). Thus, it is worth to further investigate into the contingency effects which seem to be immanent in purchasing performance models. Hence, both theory building and empirical testing of contingency effects are envisaged next steps in progressing with this research.

\section{References}

Bals, L., Hartmann, E., \& Ritter, T. (2009). Barriers of purchasing departments' involvement in marketing service procurement. Industrial Marketing Management, 38(8), 892-902.

Chen, J.-s., Tsou, H. T., \& Huang, A. Y.-h. (2009). Service delivery innovation: Antecedents and impact on firm performance. Journal of service research, 12(1), 36-55.

de Beuckelaer, A., \& Wagner, S. M. (2007). Qualitative and quantitative international research: The issue of overlooking alternative explanations. Journal of Purchasing \& Supply Management, 13(3), 213-215.

Galbraith, J. R. (1973): Designing complex organizations, Addison-Wesley: Reading.

Garrido-Samaniego, M. J., \& Gutiérrez-Cillán, J. (2004). Determinants of influence and participation in the buying center. An analysis of Spanish industrial companies. Journal of Business \& Industrial Marketing, 19(5), 320-336.

Ghoshal, S., \& Nohria, N. (1993): Horses for courses: organizational forms for multinational corporations. Sloan Management Review, 34(2), 23-35.

Giannakis, M., Doran, D., \& Chen, S. (2012). The Chinese paradigm of global supplier relationships: Social control, formal interactions and the mediating role of culture. Industrial Marketing Management, 41(5), 831-840.

Giunipero, L., Handfield, R. B., \& Eltantawy, R. (2006). Supply management's evolution: key skill sets for the supply manager of the future. International Journal of Operations \& Production Management, 26(7), 822-844.

Giunipero, L. C., \& Pearcy, D. H. (2000). World-Class Purchasing Skills An Empirical Investigation. The Journal of Supply Chain Management, 36(4), 4-13.

Glock, C. H., \& Hochrein, S. (2011). Purchasing Organization and Design: A Literature Review. Business Research, 4(2), 149-191.

González-Benito, J. (2007). A theory of purchasing's contribution to business performance. Journal of Operations Management, 25(4), 901-917.

González-Benito, J. (2010). Supply strategy and business performance. International Journal of Operations \& Production Management, 30(8), 774-797.

Gonzalez-Padron, T., Hult, G. T. M., \& Calantone, R. (2008). Exploiting innovative opportunities in global purchasing: An assessment of ethical climate and relationship performance. Industrial Marketing Management, 37(1), 69-82.

Hair, J. F., Hult, T. M., Ringle, C. M., \& Sarstedt, M. (2014). A primer on partial least squares structural equations modeling (PLS-SEM). Thousand Oaks: SAGE Publications.

Hartmann, E., Trautmann, G., \& Jahns, C. (2008). Organisational design implications of global sourcing: A multiple case study analysis on the application of control mechanisms. 
Journal of Purchasing \& Supply Management, 14(1), 28-42.

Hultman, J., Johnsen, T., Johnsen, R., \& Hertz, S. (2012). An interaction approach to global sourcing: A case study of IKEA. Journal of Purchasing \& Supply Management, 18(1), 9-21.

Johnston, W. J., \& Bonoma, T. V. (1981). The Buying Center: Structure and Interaction Patterns. The Journal of Marketing Theory and Practice, 45(3), 143-156.

Karjalainen, K., \& Salmi, A. (2013). Continental differences in purchasing strategies and tools. International Business Review, 22(1), 112-125.

Kerkfeld, D., \& Hartmann, E. (2012). Maximizing impact of investments into purchasing and supply management. International Journal of Physical Distribution \& Logistics Management, 42(5), 464-489.

Kusaba, K., Moser, R., \& Rodrigues, A. M. (2011). Low-Cost Country Sourcing Competence: A Conceptual Framework and Empirical Analysis. The Journal of Supply Chain Management, 47(4), 73-93.

Murray, J. Y., Kotabe, M., \& Zhou, J. N. (2005). Strategic alliance-based sourcing and market performance: Evidence from foreign firms operating in China. Journal of International Business Studies, 36(2), 187-208.

Narasimhan, R., \& Das, A. (2001). The impact of purchasing integration and practices on manufacturing performance. Journal of Operations Management, 19(5), 593-609.

Paulraj, A. (2011). Understanding the relationships between internal resources and capabilities, sustainable supply management and organizational sustainability. The Journal of Supply Chain Management, 47(1), 71-89.

Petersen, K. J., Frayer, D. J., \& Scannell, T. V. (2000). An Empirical Investigation of Global Sourcing Strategy Effectiveness. The Journal of Supply Chain Management, 36(2), 2938.

Quintens, L., Pauwels, P., \& Matthyssens, P. (2006a). Global purchasing strategy: Conceptualization and measurement. Industrial Marketing Management, 35(7), 881891.

Quintens, L., Pauwels, P., \& Matthyssens, P. (2006b). Global purchasing: State of the art and research directions. Journal of Purchasing \& Supply Management, 12(4), 170-181.

Ringle, C. M., Wende, S., \& Becker, J.-M. (2014). SmartPLS 3.0. Hamburg. http://www.smartpls.com

Sanchez-Rodriguez, C., Hemsworth, D., Martinez-Lorente, A. R., \& Clavel, J. G. (2006). An empirical study on the impact of standardization of materials and purchasing procedures on purchasing and business performance. Supply Chain Management: An International Journal, 11(1), 56-64.

Trent, R. J., \& Monczka, R. M. (2003). Understanding integrated global sourcing. International Journal of Physical Distribution \& Logistics Management, 33(7), 607-639.

Tressin, T., \& Richter, N. F. (2014). Determinants of International Purchasing Success: An Analysis of the Status Quo of Research. Management and Organizational Studies, 1(2), 129-147.

Wang, J., Singh, P. J., Samson, D., \& Power, D. (2011). Sourcing from China: experiences of Australian firms. Supply Chain Management: An International Journal, 16(6), 419-427.

Weber, M., Hiete, M., Lauer, L., \& Rentz, O. (2010). Low cost country sourcing and its effects on the total cost of ownership structure for a medical devices manufacturer. Journal of Purchasing \& Supply Management, 16(1), 4-16. 